\title{
Progress Toward Polio Eradication — Worldwide, January 2019-June 2021
}

John Paul Bigouette, $\mathrm{PhD}^{1,2}$; Amanda L. Wilkinson, $\mathrm{PhD}^{2}$; Graham Tallis, $\mathrm{MPH}^{3}$; Cara C. Burns, $\mathrm{PhD}^{4}$; Steven G. F. Wassilak, $\mathrm{MD}^{2}$; John F. Vertefeuille, $\mathrm{PhD}^{2}$

In 1988, when the Global Polio Eradication Initiative (GPEI) began, polio paralyzed $>350,000$ children across 125 countries. Today, only one of three wild poliovirus serotypes, type 1 (WPV1), remains in circulation in only two countries, Afghanistan and Pakistan. This report summarizes progress toward global polio eradication during January 1, 2019June 30, 2021 and updates previous reports $(1,2)$. In 2020, 140 cases of WPV1 were reported, including 56 in Afghanistan (a 93\% increase from 29 cases in 2019) and 84 in Pakistan (a 43\% decrease from 147 cases in 2019). As GPEI focuses on the last endemic WPV reservoirs, poliomyelitis outbreaks caused by circulating vaccine-derived poliovirus (cVDPV) have emerged as a result of attenuated oral poliovirus vaccine (OPV) virus regaining neurovirulence after prolonged circulation in underimmunized populations (3). In 2020, 32 countries reported cVDPV outbreaks (four type 1 [cVDPV1], 26 type 2 [cVDPV2] and two with outbreaks of both); 13 of these countries reported new outbreaks. The updated GPEI Polio Eradication Strategy 2022-2026 (4) includes expanded use of the type 2 novel oral poliovirus vaccine (nOPV2) to avoid new emergences of cVDPV2 during outbreak responses (3). The new strategy deploys other tactics, such as increased national accountability, and focused investments for overcoming the remaining barriers to eradication, including program disruptions and setbacks caused by the COVID-19 pandemic.

\section{Polio Vaccination}

In worldwide immunization programs, OPV and at least 1 dose of injectable, inactivated poliovirus vaccine (IPV) are routinely used. Because IPV contains all three poliovirus serotypes, it protects against disease in children who seroconvert after vaccination; however, it does not prevent poliovirus transmission. In 2016, a global coordinated switch occurred from trivalent OPV (tOPV), which contains Sabin strain types 1, 2, and 3 to bivalent OPV (bOPV), which contains Sabin strain

\section{INSIDE}

1136 Trends in Nonfatal and Fatal Overdoses Involving Benzodiazepines - 38 States and the District of Columbia, 2019-2020

1142 Mental Health and Substance Use Among Adults with Disabilities During the COVID-19 Pandemic United States, February-March 2021

1150 New COVID-19 Cases and Hospitalizations Among Adults, by Vaccination Status - New York, May 3July 25, 2021

1156 Sustained Effectiveness of Pfizer-BioNTech and Moderna Vaccines Against COVID-19 Associated Hospitalizations Among Adults - United States, March-July 2021

1163 Effectiveness of Pfizer-BioNTech and Moderna Vaccines in Preventing SARS-CoV-2 Infection Among Nursing Home Residents Before and During Widespread Circulation of the SARS-CoV-2 B.1.617.2 (Delta) Variant - National Healthcare Safety Network, March 1-August 1, 2021

1167 Effectiveness of COVID-19 Vaccines in Preventing SARS-CoV-2 Infection Among Frontline Workers Before and During B.1.617.2 (Delta) Variant Predominance — Eight U.S. Locations, December 2020-August 2021

1170 SARS-CoV-2 Infections and Hospitalizations Among Persons Aged $\geq 16$ Years, by Vaccination Status Los Angeles County, California, May 1-July 25, 2021

1177 Notes from the Field: Illicit Benzodiazepines Detected in Patients Evaluated in Emergency Departments for Suspected Opioid Overdose Four States, October 6, 2020-March 9, 2021

1181 QuickStats

Continuing Education examination available at https://www.cdc.gov/mmwr/mmwr_continuingEducation.html

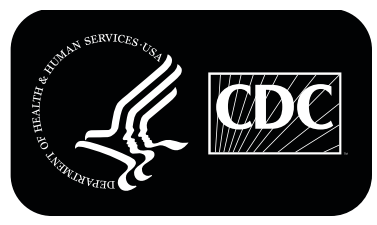

U.S. Department of Health and Human Services Centers for Disease Control and Prevention 
types 1 and 3. WPV2 was declared eradicated in 2015, and cVDPV2 was the predominant cause of cVDPV outbreaks after the last WPV2 case was detected in 1999. The use of monovalent OPV Sabin strain type 2 (mOPV2) is reserved for cVDPV2 outbreak responses. In November 2020, the World Health Organization (WHO) granted Emergency Use Listing (EUL) for genetically stabilized nOPV2 to be used in a limited number of countries that have met readiness criteria for initial use* of nOPV2 (5) in response to outbreaks.

In 2020, the estimated global infant coverage with 3 doses of poliovirus vaccine ( $\mathrm{Pol} 3$ ) by age 1 year was $83 \%$ (6). However, substantial variation in coverage exists by WHO region, nationally, and subnationally. In the two countries with endemic WPV (Afghanistan and Pakistan), 2020 POL3 coverage was $75 \%$ and $83 \%$, respectively (6); estimated coverage in subnational areas with transmission is much lower.

In 2019, GPEI supported 199 supplementary immunization activities (SIAs) ${ }^{\dagger}$ in 42 countries with approximately 1 billion bOPV, 20 million IPV, 32 million monovalent OPV type 1 (mOPV1), and 142 million mOPV2 doses administered. In 2020, 149 SIAs were conducted in 30 countries with approximately 696 million bOPV, 6 million IPV, 4 million mOPV1,

\footnotetext{
*Authorization for wider use under EUL is pending review of safety and effectiveness data from the initial use.

${ }^{\dagger}$ Mass immunization campaigns intended to interrupt poliovirus circulation by immunizing every child aged $<5$ years with 2 OPV doses, regardless of previous immunization status.
}

228 million mOPV2, and 51 million tOPV doses administered; tOPV was used during four SIAs in Afghanistan and Pakistan, where cocirculation of WPV1 and cVDPV2 requires tOPV for efficiency in scheduling and implementing SIAs; GPEI authorized restarting filling of tOPV stocks for this purpose. In 2021, approximately 136 million nOPV2 doses have been released in eight countries approved for initial use (Benin, Chad, Congo, Liberia, Niger, Nigeria, Sierra Leone, and Tajikistan). SIAs continue to be affected by the COVID-19 pandemic ${ }^{\mathbb{S}}$ in 2021.

\section{Poliovirus Surveillance}

WPV and cVDPV transmission are detected primarily through surveillance for acute flaccid paralysis (AFP) among children aged $<15$ years with testing of stool specimens at one of $145 \mathrm{WHO}$-accredited laboratories of the Global Polio Laboratory Network (7). During January-September 2020, the number of reported AFP cases declined 33\% compared with the same period in 2019 (8). Environmental surveillance (testing of sewage for poliovirus) can supplement AFP surveillance; however, environmental sampling also declined somewhat during this period. Current data indicate that the COVID-19 pandemic has continued to limit AFP surveillance sensitivity.

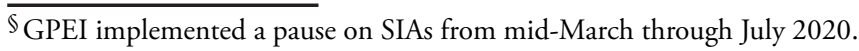

The MMWR series of publications is published by the Center for Surveillance, Epidemiology, and Laboratory Services, Centers for Disease Control and Prevention (CDC), U.S. Department of Health and Human Services, Atlanta, GA 30329-4027.

Suggested citation: [Author names; first three, then et al., if more than six.] [Report title]. MMWR Morb Mortal Wkly Rep 2021;70:[inclusive page numbers].

\section{Centers for Disease Control and Prevention Rochelle P. Walensky, MD, MPH, Director \\ Debra Houry, MD, MPH, Acting Principal Deputy Director \\ Daniel B. Jernigan, MD, MPH, Deputy Director for Public Health Science and Surveillance \\ Rebecca Bunnell, PhD, MEd, Director, Office of Science \\ Jennifer Layden, MD, PhD, Deputy Director, Office of Science \\ Michael F. Iademarco, MD, MPH, Director, Center for Surveillance, Epidemiology, and Laboratory Services \\ MMWR Editorial and Production Staff (Weekly)}

Charlotte K. Kent, PhD, MPH, Editor in Chief Jacqueline Gindler, MD, Editor

Brian A. King, PhD, MPH, Guest Science Editor

Paul Z. Siegel, MD, MPH, Associate Editor

Mary Dott, MD, MPH, Online Editor

Terisa F. Rutledge, Managing Editor

Teresa M. Hood, MS, Lead Technical Writer-Editor

Leigh Berdon, Glenn Damon, Soumya Dunworth, PhD, Srila Sen, MA, Stacy Simon, MA,

Jeffrey D. Sokolow, MA, Morgan Thompson, Technical Writer-Editors

Matthew L. Boulton, MD, MPH

Carolyn Brooks, ScD, MA

Jay C. Butler, MD

Virginia A. Caine, MD

Jonathan E. Fielding, MD, MPH, MBA

David W. Fleming, MD
Martha F. Boyd, Lead Visual Information Specialist

Alexander J. Gottardy, Maureen A. Leahy,

Julia C. Martinroe, Stephen R. Spriggs,

Brian Taitt, Tong Yang,

Visual Information Specialists

Quang M. Doan, MBA, Phyllis H. King,

Terraye M. Starr, Moua Yang,

Information Technology Specialists

MMWR Editorial Board

Timothy F. Jones, MD, Chairman

William E. Halperin, MD, DrPH, MPH

Jewel Mullen, MD, MPH, MPA

Jeff Niederdeppe, $\mathrm{PhD}$

Celeste Philip, MD, MPH

Patricia Quinlisk, MD, MPH

Patrick L. Remington, MD, MPH
Ian Branam, MA, Ginger Redmon, MA, Co-Acting Lead Health Communication Specialist Shelton Bartley, MPH,

Lowery Johnson, Amanda Ray,

Jacqueline N. Sanchez, MS,

Health Communication Specialists Will Yang, MA,

Visual Information Specialist
Carlos Roig, MS, MA William Schaffner, MD

Nathaniel Smith, MD, MPH

Morgan Bobb Swanson, BS 
The continued strengthening of both surveillance systems, particularly in priority countries, 9 is critical to tracking progress and documenting the absence of poliovirus transmission.

\section{Reported Poliovirus Cases and Isolations}

Countries reporting WPV cases and isolations. Since 2016, no WPV cases have been identified outside of Afghanistan and Pakistan. Of the 176 WPV1 cases reported in 2019, 29 (16\%) occurred in Afghanistan and 147 (84\%) in Pakistan (Figure) (Table 1).

In 2020, Afghanistan reported 56 WPV1 cases representing a $93 \%$ increase from cases reported in the previous year; cases

\footnotetext{
2020 priority countries: African Region: Angola, Benin, Burkina Faso, Cameroon, Central African Republic, Chad, Congo, Côte d'Ivoire, Democratic Republic of the Congo, Eritrea, Ethiopia, Ghana, Guinea, Kenya, Liberia, Madagascar, Mali, Mauritania, Mozambique, Niger, Nigeria, Senegal, Sierra Leone, South Sudan, Togo, and Zambia; Eastern Mediterranean Region: Afghanistan, Egypt, Iran, Iraq, Libya, Pakistan, Somalia, Sudan, Syria, and Yemen; European Region: Tajikistan and Uzbekistan; South-East Asia Region: Burma (Myanmar); Western Pacific Region: Malaysia and Philippines.
}

were found across 38 districts compared with 20 districts in 2019. As of August 3, 2021, one WPV1 case was reported in Afghanistan in 2021, a 97\% decrease compared with the first 6 months of 2020. Pakistan reported 84 WPV1 cases from 39 districts in 2020 , representing a $43 \%$ decrease from the 147 cases reported in 43 districts during 2019. One WPV1 case has been reported during January-June 2021, from Balochistan province, a 98\% decrease from the $60 \mathrm{WPV} 1$ cases from five provinces during the same 2020 period. This period accounted for $71 \%$ of all Pakistan WPV1 cases in 2020. In both countries, the number of orphan WPV1 isolates (those with $\leq 98.5 \%$ genetic identity with other isolates) from AFP cases increased from five of $176(3 \%)$ in 2019 to 18 of 140 $(13 \%)$ in 2020 , signifying an increase in AFP surveillance gaps in 2020 (7).

Environmental surveillance in Afghanistan detected WPV1 in $35(8 \%)$ of 418 sewage samples collected during 2020 and in 57 (22\%) of 264 samples in 2019 (Table 2). In Pakistan, WPV1 was detected in 434 (52\%) of 830 sewage samples

FIGURE. Number of wild poliovirus type 1 cases, by country and month of paralysis onset — worldwide, January 2019-June 2021*

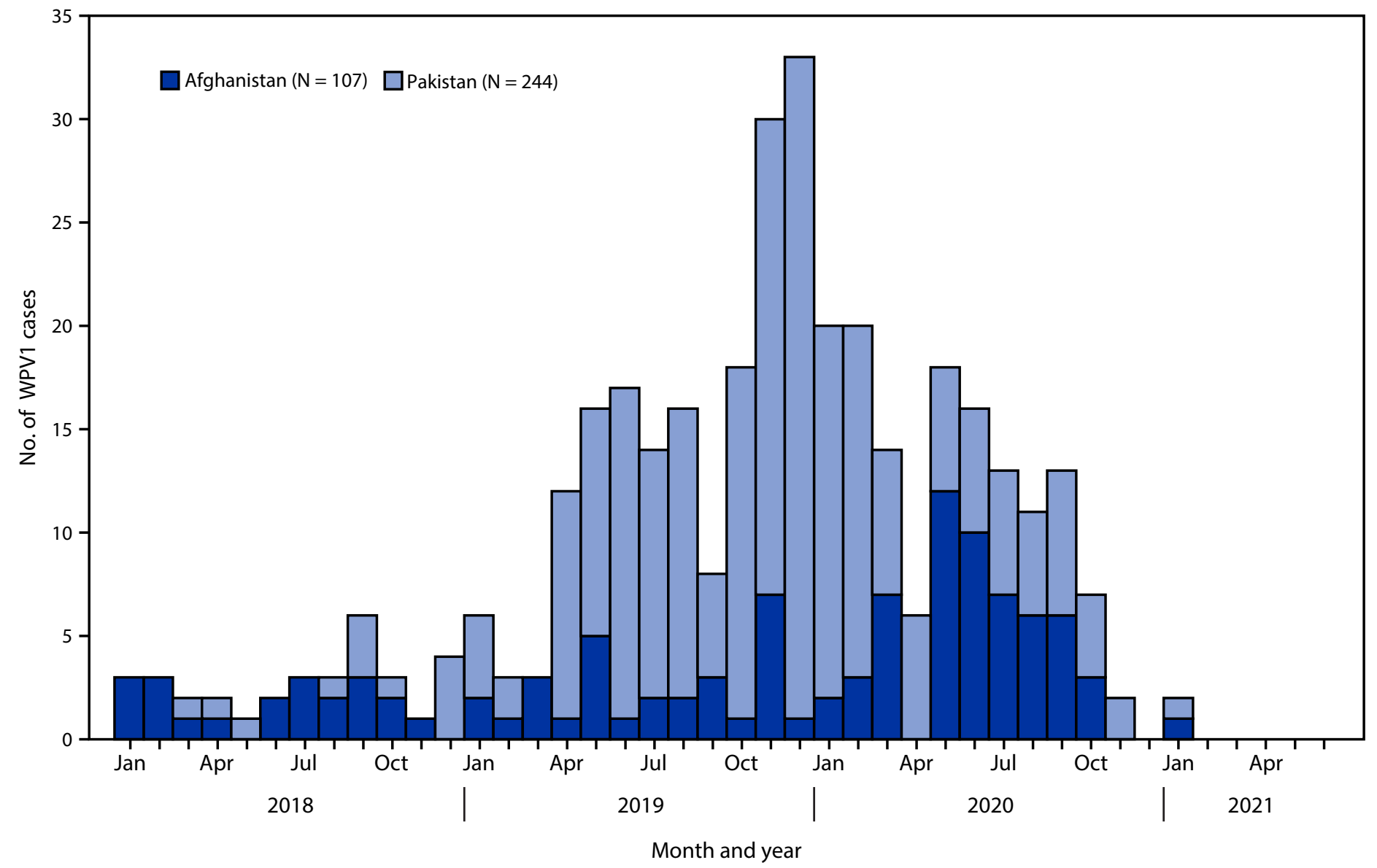

Abbreviation: WPV1 $=$ wild poliovirus type 1.

* Data are current as of August 3, 2021. 
TABLE 1. Number of poliovirus cases, by country — worldwide, January 1, 2019-June 30, $2021 *$

\begin{tabular}{|c|c|c|c|c|c|c|c|c|}
\hline \multirow[b]{3}{*}{ Country (cVDPV type) } & \multicolumn{8}{|c|}{ Reporting period } \\
\hline & \multicolumn{2}{|c|}{2019} & \multicolumn{2}{|c|}{2020} & \multicolumn{2}{|c|}{ Jan-Jun 2020} & \multicolumn{2}{|c|}{ Jan-Jun 2021} \\
\hline & WPV1 & cVDPV & WPV1 & cVDPV & WPV1 & cVDPV & WPV1 & cVDPV \\
\hline \multicolumn{9}{|c|}{ Countries with endemic WPV1 transmission } \\
\hline Afghanistan (2) ${ }^{\dagger}$ & 29 & 0 & 56 & 308 & 34 & 54 & 1 & 43 \\
\hline Pakistan (2) & 147 & 22 & 84 & 135 & 60 & 52 & 1 & 8 \\
\hline \multicolumn{9}{|l|}{ Countries with reported cVDPV cases } \\
\hline Angola (2) & 0 & 138 & 0 & 3 & 0 & 3 & 0 & 0 \\
\hline Benin (2) & 0 & 8 & 0 & 3 & 0 & 2 & 0 & 2 \\
\hline Burkina Faso (2) & 0 & 1 & 0 & 65 & 0 & 26 & 0 & 1 \\
\hline Burma (Myanmar) $(2)^{\S}$ & 0 & 6 & 0 & 0 & 0 & 0 & 0 & 0 \\
\hline Cameroon $(2)^{\dagger}$ & 0 & 0 & 0 & 7 & 0 & 4 & 0 & 0 \\
\hline Central African Republic (2) & 0 & 21 & 0 & 4 & 0 & 1 & 0 & 0 \\
\hline Chad (2) & 0 & 11 & 0 & 99 & 0 & 57 & 0 & 0 \\
\hline China (2) & 0 & 1 & 0 & 0 & 0 & 0 & 0 & 0 \\
\hline Republic of the Congo $(2)^{\dagger}$ & 0 & 0 & 0 & 2 & 0 & 0 & 0 & 2 \\
\hline Côte d'Ivoire (2) ${ }^{\dagger}$ & 0 & 0 & 0 & 61 & 0 & 39 & 0 & 0 \\
\hline Democratic Republic of the Congo (2) & 0 & 88 & 0 & 81 & 0 & 54 & 0 & 10 \\
\hline Ethiopia (2) & 0 & 14 & 0 & 36 & 0 & 17 & 0 & 6 \\
\hline Ghana (2) & 0 & 18 & 0 & 12 & 0 & 12 & 0 & 0 \\
\hline Guinea $(2)^{\dagger}$ & 0 & 0 & 0 & 44 & 0 & 23 & 0 & 6 \\
\hline Liberia $(2)^{\dagger}$ & 0 & 0 & 0 & 0 & 0 & 0 & 0 & 3 \\
\hline Madagascar (1) ${ }^{\dagger}$ & 0 & 0 & 0 & 2 & 0 & 0 & 0 & 6 \\
\hline Malaysia (1) & 0 & 3 & 0 & 1 & 0 & 1 & 0 & 0 \\
\hline Mali $(2)^{\dagger}$ & 0 & 0 & 0 & 48 & 0 & 6 & 0 & 0 \\
\hline Niger (2) & 0 & 1 & 0 & 10 & 0 & 6 & 0 & 0 \\
\hline Nigeria (2) & 0 & 18 & 0 & 8 & 0 & 2 & 0 & 65 \\
\hline Philippines $(1,2)$ & 0 & 14 & 0 & 1 & 0 & 1 & 0 & 0 \\
\hline Senegal $(2)^{\dagger}$ & 0 & 0 & 0 & 0 & 0 & 0 & 0 & 13 \\
\hline Sierra Leone $(2)^{\dagger}$ & 0 & 0 & 0 & 10 & 0 & 0 & 0 & 4 \\
\hline Somalia (2) & 0 & 3 & 0 & 14 & 0 & 2 & 0 & 0 \\
\hline South Sudan (2) ${ }^{\dagger}$ & 0 & 0 & 0 & 50 & 0 & 2 & 0 & 9 \\
\hline Sudan $(2)^{\dagger}$ & 0 & 0 & 0 & 58 & 0 & 10 & 0 & 0 \\
\hline Tajikistan (2) ${ }^{\dagger}$ & 0 & 0 & 0 & 1 & 0 & 0 & 0 & 23 \\
\hline Togo $(2)$ & 0 & 8 & 0 & 9 & 0 & 9 & 0 & 0 \\
\hline Yemen (1) & 0 & 1 & 0 & 31 & 0 & 22 & 0 & 3 \\
\hline Zambia (2) & 0 & 2 & 0 & 0 & 0 & 0 & 0 & 0 \\
\hline
\end{tabular}

Abbreviations: $\mathrm{CVDPV}=$ circulating vaccine-derived poliovirus; WPV1 = Wild poliovirus type 1.

* Data are current as of August 3, 2021.

+ New cVDPV cases reported after December 31, 2019.

$\S$ For this country, MMWR uses the U.S. State Department short-form name "Burma"; the World Health Organization uses "Myanmar."

I Reported two cVDPV type 1 cases and 12 cVDPV type 2 cases in 2019, one cVDPV type 2 case in 2020.

collected in 2020, and 44\% (379/854) of sewage samples were WPV1-positive in 2019. In 2019, three (4\%) of the 71 sewage samples collected in Iran contained WPV1 isolates; no positive environmental samples or cases have been reported since then.

Countries reporting cVDPV cases and isolations. During January 2019-June 2021, cVDPV transmission was identified in 32 countries; 13 countries were affected by new cVDPV outbreaks in 2020. Afghanistan reported 308 cVDPV2 cases in 2020 compared with no cases in 2019. Pakistan reported 135 cVDPV2 cases in 2020, more than a fivefold increase from the 22 reported in 2019. To date in 2021, 195 cVDPV2 cases have been identified globally, including 43 in Afghanistan and eight in Pakistan.

\section{Discussion}

With the August 2020 certification of the African Region as WPV-free, ${ }^{* *}$ five of the six WHO regions, representing over $90 \%$ of the world's population, are now free of wild polioviruses. Given this achievement, GPEI is focusing efforts on two goals: interrupting persistent WPV1 transmission in Pakistan and Afghanistan and stopping all current outbreaks of cVDPV2. To reach these goals, in June 2021, GPEI released a revised 5-year strategy for polio eradication that aims to address persistent challenges and recover from setbacks exacerbated by the COVID-19 pandemic (4).

Guided by the Polio Eradication Strategy 2022-2026, GPEI partners and in-country stakeholders are to adopt a full emergency posture and assume more accountability for eradication

** https://www.africakicksoutwildpolio.com 
TABLE 2. Number of circulating wild polioviruses and circulating vaccine-derived polioviruses detected through environmental surveillance worldwide, January 1, 2019-June 30, 2021*

\begin{tabular}{|c|c|c|c|c|c|c|c|c|}
\hline \multirow[b]{2}{*}{ Country } & \multicolumn{2}{|c|}{ Jan 1-Dec 31, 2019} & \multicolumn{2}{|c|}{ Jan 1-Dec 31, 2020} & \multicolumn{2}{|c|}{ Jan 1-Jun 30, 2020} & \multicolumn{2}{|c|}{ Jan 1-Jun 30, 2021} \\
\hline & $\begin{array}{c}\text { No. of } \\
\text { samples }\end{array}$ & $\begin{array}{l}\text { No. (\%) with } \\
\text { isolates }\end{array}$ & $\begin{array}{c}\text { No. of } \\
\text { samples }\end{array}$ & $\begin{array}{l}\text { No. (\%) with } \\
\text { isolates }\end{array}$ & $\begin{array}{c}\text { No. of } \\
\text { samples }\end{array}$ & $\begin{array}{l}\text { No. (\%) with } \\
\text { isolates }\end{array}$ & $\begin{array}{c}\text { No. of } \\
\text { samples }\end{array}$ & $\begin{array}{l}\text { No. (\%) with } \\
\text { isolates }\end{array}$ \\
\hline \multicolumn{9}{|c|}{ Countries with reported WPV1-positive samples (no. and percentage of isolates refer to WPV1) } \\
\hline Afghanistan & 264 & $57(22)$ & 418 & $35(8)$ & 172 & $22(13)$ & 213 & $1(1)$ \\
\hline Iran & 71 & $3(4)$ & 43 & $0(-)$ & 0 & $0(-)$ & 0 & $0(-)$ \\
\hline Pakistan & 854 & $379(44)$ & 830 & $434(52)$ & 414 & $238(57)$ & 444 & $59(13)$ \\
\hline \multicolumn{9}{|c|}{ Countries with reported cVDPV-positive samples (cVDPV type) (no. and percentage of isolates refer to cVDPVs) } \\
\hline Afghanistan (2) & 264 & $0(-)$ & 418 & $175(42)$ & 172 & $46(27)$ & 213 & $40(19)$ \\
\hline Angola (2) & 106 & $17(16)$ & 98 & $0(-)$ & 47 & $0(-)$ & 15 & $0(-)$ \\
\hline Benin (2) & 37 & $0(-)$ & 70 & $5(7)$ & 31 & $0(-)$ & 52 & $1(2)$ \\
\hline Cameroon (2) & 602 & $4(1)$ & 273 & $9(3)$ & 134 & $4(3)$ & 187 & $0(-)$ \\
\hline Central African Republic (2) & 149 & $10(7)$ & 97 & $2(2)$ & 43 & $2(5)$ & 48 & $0(-)$ \\
\hline Chad (2) & 198 & $10(5)$ & 77 & $3(4)$ & 55 & $3(5)$ & 26 & $0(-)$ \\
\hline China (3) & 0 & $0(-)$ & 0 & $0(-)$ & 0 & $0(-)$ & 1 & $1(100)$ \\
\hline Republic of the Congo (2) & 0 & $0(-)$ & 12 & $1(8)$ & 0 & $0(-)$ & 213 & $1(1)$ \\
\hline Cote d'Ivoire (2) & 154 & $7(5)$ & 130 & $91(70)$ & 88 & $62(70)$ & 42 & $0(-)$ \\
\hline Democratic Republic of the Congo (2) & 294 & $0(-)$ & 170 & $1(1)$ & 78 & $1(1)$ & 145 & $0(-)$ \\
\hline Egypt (2) & 703 & $0(-)$ & 550 & $1(0)$ & 267 & $0(-)$ & 313 & $10(3)$ \\
\hline Ethiopia (2) & 159 & $3(2)$ & 51 & $2(4)$ & 33 & $0(-)$ & 15 & $0(-)$ \\
\hline Gambia (2) & 0 & $0(-)$ & 0 & $0(-)$ & 0 & $0(-)$ & 9 & $2(22)$ \\
\hline Ghana (2) & 202 & $17(8)$ & 184 & $20(11)$ & 100 & $19(19)$ & 99 & $0(-)$ \\
\hline Guinea (2) & 103 & $0(-)$ & 67 & $1(1)$ & 38 & $0(-)$ & 61 & $0(-)$ \\
\hline $\operatorname{Iran}(2)$ & 74 & $0(-)$ & 43 & $3(7)$ & 12 & $0(-)$ & 25 & $1(4)$ \\
\hline Kenya (2) & 317 & $0(-)$ & 193 & $1(1)$ & 92 & $0(-)$ & 101 & $1(1)$ \\
\hline Liberia (2) & 0 & $0(-)$ & 34 & $6(18)$ & 15 & $0(-)$ & 47 & $12(26)$ \\
\hline Madagascar (1) & 520 & $0(-)$ & 351 & $0(-)$ & 232 & $0(-)$ & 134 & $12(9)$ \\
\hline Malaysia $(1,2)$ & 13 & $12(92)$ & 76 & $12(16)$ & 50 & $12(24)$ & 22 & $0(-)$ \\
\hline Mali (2) & 48 & $0(-)$ & 44 & $4(9)$ & 22 & $2(9)$ & 27 & $0(-)$ \\
\hline Niger (2) & 293 & $0(-)$ & 157 & $7(4)$ & 93 & $1(1)$ & 73 & $0(-)$ \\
\hline Nigeria (2) & 2071 & $60(3)$ & 1294 & $5(0)$ & 625 & $0(-)$ & 868 & $34(4)$ \\
\hline Pakistan (2) & 855 & $36(4)$ & 830 & $135(16)$ & 414 & $35(8)$ & 444 & $32(7)$ \\
\hline Philippines $(1,2)$ & 67 & $32(48)$ & 80 & $4(5)$ & 50 & $4(8)$ & 18 & $0(-)$ \\
\hline Senegal (2) & 56 & $0(-)$ & 27 & $1(4)$ & 14 & $0(-)$ & 10 & $4(40)$ \\
\hline Somalia (2) & 92 & $5(5)$ & 88 & $26(30)$ & 52 & $18(35)$ & 52 & $1(2)$ \\
\hline South Sudan (2) & 111 & $0(-)$ & 85 & $6(7)$ & 57 & $0(-)$ & 24 & $0(-)$ \\
\hline Sudan (2) & 65 & $0(-)$ & 50 & $14(28)$ & 20 & $3(15)$ & 30 & $0(-)$ \\
\hline Tajikistan (2) & 0 & $0(-)$ & 0 & $0(一)$ & 0 & $0(一)$ & 14 & $13(93)$ \\
\hline Uganda (2) & 56 & $0(-)$ & 58 & $0(-)$ & 24 & $0(-)$ & 36 & $2(6)$ \\
\hline
\end{tabular}

Abbreviations: $\mathrm{CVDPV}=$ circulating vaccine-derived poliovirus; WPV1 = Wild poliovirus type 1 .

* Data are current as of August 3, 2021.

at every level of the program (4). The strategy elevates efforts in the highest-risk countries and promotes health service integration, surveillance improvement, and community engagement to enhance campaign quality through increased political advocacy to ensure timely and effective emergency outbreak SIA responses through improved government support of implementation.

Although Pakistan and Afghanistan face distinct challenges, they are linked epidemiologically because of high rates of crossborder population movement. Transit-point vaccination must be maintained as emigration from Afghanistan potentially increases in 2021. The beginning of each year is typically the low season for WPV1 transmission in both countries, and AFP surveillance sensitivity has decreased. During 2019, the Pakistan polio program suffered from increased vaccine resistance fed by social media misinformation and faced continued operational problems in some localities. The program changed its management oversight and enhanced efforts to overcome community mistrust to decrease vaccine hesitancy (9). Inroads to improving the effectiveness of the SIAs have also been made in 2020 (4). Although the proportion of Pakistan environmental samples that are WPV-positive remains high in 2021 to date, the decrease from the same period in 2020 is worth noting.

In Afghanistan, the main challenges to ending poliovirus transmission are the inability to reach all children in critical areas near reservoirs in Pakistan and increasing political instability. The polio program in Afghanistan has continued to operate for many years, even during periods of insecurity and escalating conflict. Although negotiations with local leaders in Afghanistan facilitated vaccination efforts at one time, restrictions on vaccinations have persisted in areas controlled by insurgent groups since the October 2018 ban on house-to-house campaigns, which has 


\section{Summary}

What is already known about this topic?

Wild poliovirus type 1 (WPV1) remains endemic in Afghanistan and Pakistan. Circulating vaccine-derived poliovirus type 2 (cVDPV2) outbreaks have increased since 2017.

What is added by this report?

From 2019 to 2020, the number of WPV1 cases increased in Afghanistan and decreased in Pakistan and the number of cVDPV2 cases increased and cVDPV2 outbreak countries increased to 32. In Afghanistan, the polio program faces challenges including an inability to reach children in critical areas and increasing political instability. The COVID-19 pandemic continues to limit the quality of immunization activities and poliovirus surveillance.

What are the implications for public health practice?

The Polio Eradication Strategy for 2022-2026 outlines measures including increased government accountability and wider use of novel, oral poliovirus vaccine type 2 that are needed to eradicate polio.

since expanded geographically $(10)$. WHO is anticipating that some negotiated access will again be possible. Other challenges include current mass population movements, clusters of vaccine refusals, and suboptimal SIA quality in some areas previously under government control (10).

Globally, cVDPV2 outbreaks increased in number and geographic extent during 2019-2020 because of delays in mOPV2 response SIAs, which were frequently of low quality. Since the switch in 2016 from tOPV to bOPV, 1,755 cases of paralytic polio have been reported from 64 cVDPV2 outbreaks in 30 countries across four WHO regions (4). ${ }^{\dagger \dagger}$ GPEI has outlined a strategy for stopping cVDPV transmission and reducing the risk of seeding new outbreaks by expanding use of nOPV2 (4). Continued monitoring will be needed to ensure safety and effectiveness while nOPV2 is brought into wider use and to ascertain whether it can replace mOPV2 (5).

The findings in this report are subject to at least one limitation. SIAs, field surveillance, and investigation activities were curtailed in 2020 because of COVID-19 pandemic mitigation measures, and laboratory testing suffered delays (8); limitations on SIA quality and surveillance sensitivity continue in 2021. On the other hand, the COVID-19 pandemic has presented opportunities to jointly increase the effectiveness of polio eradication activities and promote health services integration. For example, the global rollout of COVID-19 vaccines presents an opportunity to strengthen demand for vaccination against both COVID-19 and polio.

\footnotetext{
$\dagger \dagger$ https://polioeradication.org/polio-today/polio-now/this-week/ circulating-vaccine-derived-poliovirus/
}

Thousands of polio eradication workers worldwide continue to play a critical role in implementing countries' COVID-19 responses. Maintaining these partnerships will be important in eradicating WPV and stopping cVDPV transmission while simultaneously addressing other health priorities.

\section{Acknowledgments}

Ministries of Health of all countries; World Health Organization (WHO) Regional Office for the Eastern Mediterranean Region, Cairo, Egypt and its Polio Eradication Department, Amman, Jordan; WHO Regional Office for Africa, Brazzaville, Congo; WHO Regional Office for Europe, Copenhagen, Denmark; WHO Regional Office for the Western Pacific, Manila, Philippines; WHO Regional Office for South-East Asia, New Delhi, India; Global Polio Laboratory Network, Geneva, Switzerland and Regional Offices; Jane Iber, Mark Pallansch, Division of Viral Diseases, National Center for Immunization and Respiratory Diseases, CDC.

Corresponding author: John Paul Bigouette; JBigouette@cdc.gov; 404-834-0427.

\footnotetext{
${ }^{1}$ Epidemic Intelligence Service, CDC; ${ }^{2}$ Global Immunization Division, Center for Global Health, CDC; ${ }^{3}$ Polio Eradication Department, World Health Organization, Geneva, Switzerland; ${ }^{4}$ Division of Viral Diseases, National Center for Immunization and Respiratory Diseases, CDC.
}

All authors have completed and submitted the International Committee of Medical Journal Editors form for disclosure of potential conflicts of interest. No potential conflicts of interest were disclosed.

\section{References:}

1. Chard AN, Datta SD, Tallis G, et al. Progress toward polio eradicationworldwide, January 2018-March 2020. MMWR Morb Mortal Wkly Rep 2020;69:784-9. PMID:32584798 https://doi.org/10.15585/ mmwr.mm6925a4

2. Greene SA, Ahmed J, Datta SD, et al. Progress toward polio eradicationworldwide, January 2017-March 2019. MMWR Morb Mortal Wkly Rep 2019;68:458-62. PMID:31120868 https://doi.org/10.15585/ mmwr.mm6820a3

3. Alleman MM, Jorba J, Greene SA, et al. Update on vaccine-derived poliovirus outbreaks - worldwide, July 2019-February 2020. MMWR Morb Mortal Wkly Rep 2020;69:489-95. PMID:32324719 https:// doi.org/10.15585/mmwr.mm6916a1

4. Global Polio Eradication Initiative. Delivering on a promise: GPEI strategy 2022-2026. Geneva, Switzerland: World Health Organization; 2021. https://polioeradication.org/gpei-strategy-2022-2026/

5. World Health Organization. Implementation of novel oral polio vaccine type 2 (nOPV2) for circulating vaccine-derived poliovirus type 2 (cVDPV2) outbreak response: technical guidance for countries. World Health Organization; 2020. https://apps.who.int/iris/ handle/10665/333520

6. World Health Organization. WHO/UNICEF estimates of national immunization coverage. Geneva, Switzerland: World Health Organization; 2021. https://immunizationdata.who.int/

7. Tuma JN, Wilkinson AL, Diop OM, et al. Surveillance to track progress toward polio eradication-Worldwide, 2019-2020. MMWR Morb Mortal Wkly Rep 2021;70:667-73. PMID:33956779 https://doi. org/10.15585/mmwr.mm7018a2 
8. Zomahoun DJ, Burman AL, Snider CJ, et al. Impact of COVID-19 pandemic on global poliovirus surveillance. MMWR Morb Mortal Wkly Rep 2021;69:1648-52. PMID:33382673 https://doi.org/10.15585/ mmwr.mm695152a4

9. Hsu CH, Rehman MS, Bullard K, et al. Progress toward poliomyelitis eradication-Pakistan, January 2019-September 2020. MMWR Morb Mortal Wkly Rep 2020;69:1748-52. PMID:33211676 https://doi. org/10.15585/mmwr.mm6946a5
10. Global Polio Eradication Initiative. Afghanistan National Emergency Action Plan: Polio Eradication. Geneva, Switzerland: World Health Organization; 2021. https://polioeradication.org/wp-content/ uploads/2021/05/Afghanistan_NEAP_2021.pdf 